\title{
SOBRE A ORIGEM Quando os filhos vão para o mundo
}

ON THE ORIGIN

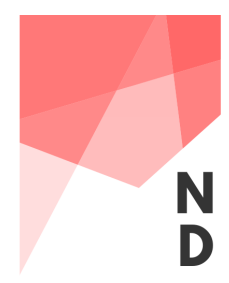

When the children go out into the world

\author{
Ana Clara Damásio \\ Universidade Federal de Goiás \\ Programa de Pós-Graduação em Antropologia Social | Goiânia, Brasil \\ anaclarasousadamasio@gmail.com | ORCID iD: 0000-0001-7426-7486
}

\begin{abstract}
Resumo
"Sobre a origem" é um ensaio que busca acompanhar Dona Nita, minha avó materna, voltando para sua roça. Nesse dia minha parente-interlocutora contoume sobre seus filhos e filhas (minhas tias e minha mãe) que foram para o mundo buscar "melhores condições de vida" e não mais retornaram para a origem. A partir do momento que seus filhos construíram uma vida no mundo, a roça, lugar que ela e meu avô tanto lutaram para conquistar, acabou sendo abandonado fisicamente, pois a terra, bichos e plantas não eram mais as narrativas de vida dos filhos e filhas da minha avó (e tampouco da netaantropóloga).
\end{abstract}

\section{Palavras-chave}

Antropologia, Família, Geração, Mundo, Fotografia.

\begin{abstract}
"Sobre a origem" is an essay that accompanies Dona Nita, my maternal grandmother, going back to her farm. On that day my relative-interlocutor told me about her sons and daughters (my aunts and my mother) who went out into the world seeking for "better conditions of life" and never returned to their homeland. From the moment her children built a life in the world, the farm, the place that she and my grandfather fought so hard to acquire, ended up being physically abandoned, for the land, animals, and plants were no longer the life narratives of my grandmother's sons and daughters (nor of the granddaughter-anthropologist).
\end{abstract}

\section{Keywords}

Anthropology, Family, Generation, World, Photography. 
$\mathrm{E}$ m Canto do Buriti, cidade com pouco mais de 20 mil habitantes localizada no sul piauiense, realizei campo no primeiro semestre de 2019 por três meses. Com o intuito de tentar compreender o envelhecimento em contexto de classe popular rural, passei a escutar sobre os filhos e filhas que estavam no mundo (Woortmann 1990). O mundo era tudo aquilo que não é Canto do Buriti [nomeado como a origem]. Entretanto, o mundo era referência usada, principalmente, em relação a São Paulo. Em 1970, os primeiros migrantes da região foram para o mundo e passaram a abrigar sobrinhos, filhos e conhecidos que eram enviados por seus pais com o intuito de que os mesmos tivessem melhores condições de vida (Sarti 1994). Nesses fluxos com-entre espaços de indivíduos que à época tinham entre 12 a 20 anos, as mulheres passaram a trabalhar majoritariamente como empregadas doméstica e os homens como serventes e pedreiros na construção civil. Nisso, décadas depois, muitos pais passaram a ter que lidar com os filhos que não queriam regressar do mundo. A terra era a narrativa dos pais, o cuidado com os bichos, a importância do plantar, colher, de manter as origens, em suma, as relações de criação (Virgílio 2018). Já os filhos que estavam no mundo passaram a ser regidos por narrativas que negavam a volta para as origens com o intuito de plantar e criar. Passaram a encarar a terra como uma vida de muito sofrimento que resultava em pouco lucro. Com isso, o presente ensaio pretende apontar para as mudanças que os filhos que estão no mundo tiveram na origem. Como Lobo (2014) ressalta na sua pesquisa realizada na ilha de Boa Vista, em Cabo Verde, o parentesco é parte constituinte dos estudos da família onde as relações de proximidade em que ocorrem as trocas realizadas cotidianamente são constituintes e essências para relações familiares. Entretanto, se as expetativas nas relações de trocas são quebradas, as relações de parentescos podem ser "esvaziadas" tornando-se apenas "memória". Mais, podem esvaziar sentidos antes importantes e constituintes de uma família. Ao mesmo tempo, a ida dos filhos para o mundo e sua recusa em voltar mostrava como o rural e urbano são espaços porosos e biviários que se retroalimentam em seus múltiplos significados construindo novos sentidos nos indivíduos e famílias a partir da migração. 


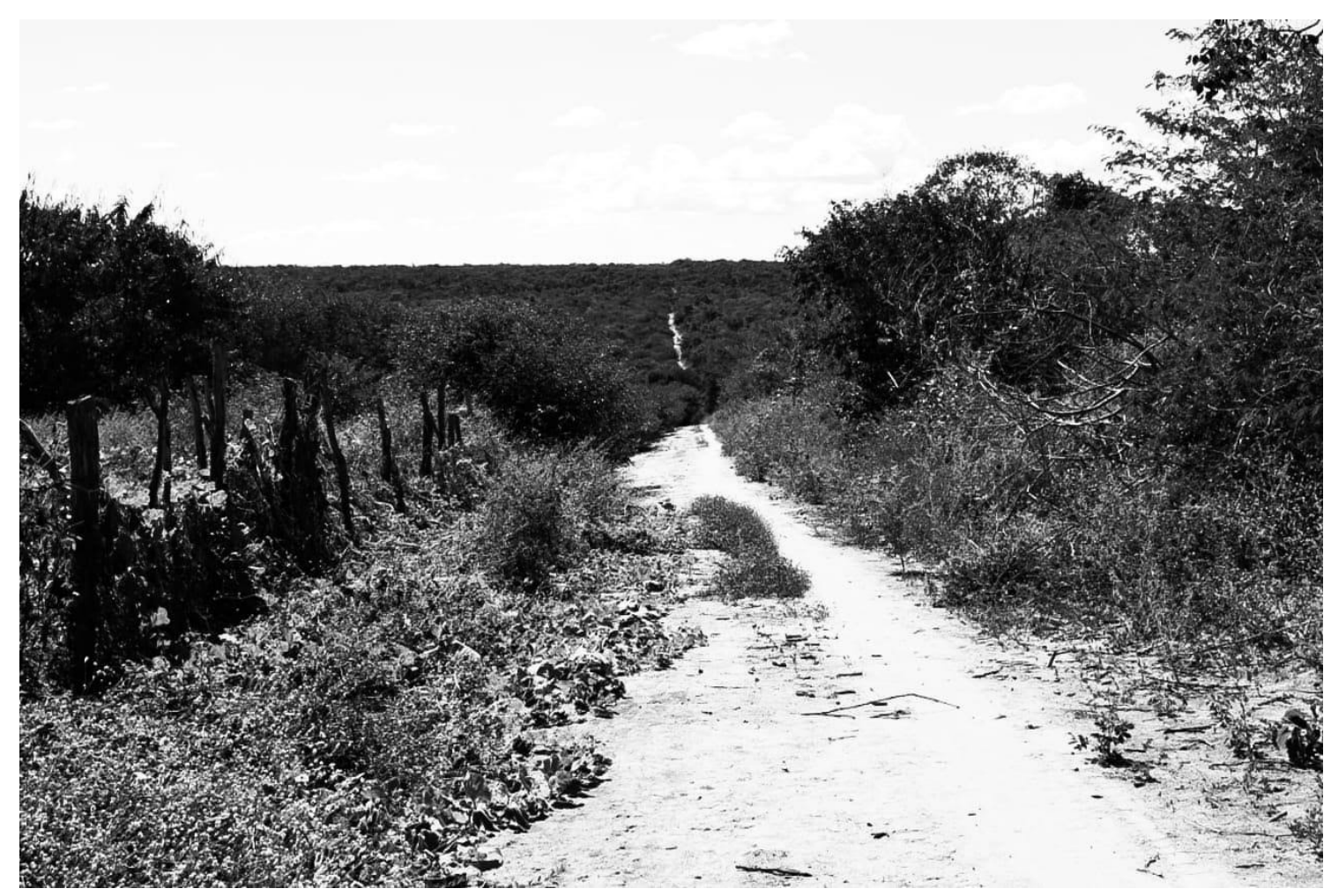

1. Caminhos que ainda estão abertos para chegar à roça. Entretanto, com muitas roças abandonadas após a morte dos pais e como os filhos no mundo, algumas estradas são consumidas tanto pela vegetação, quanto pelo tempo. Do lado esquerdo, a roça do Seu Horácio (77 anos). Do lado direito, a roça abandonada de um vizinho.

2. Casa da roça de Dona Nita (74 anos). Todos seus sete filhos estão no mundo e não voltaram.

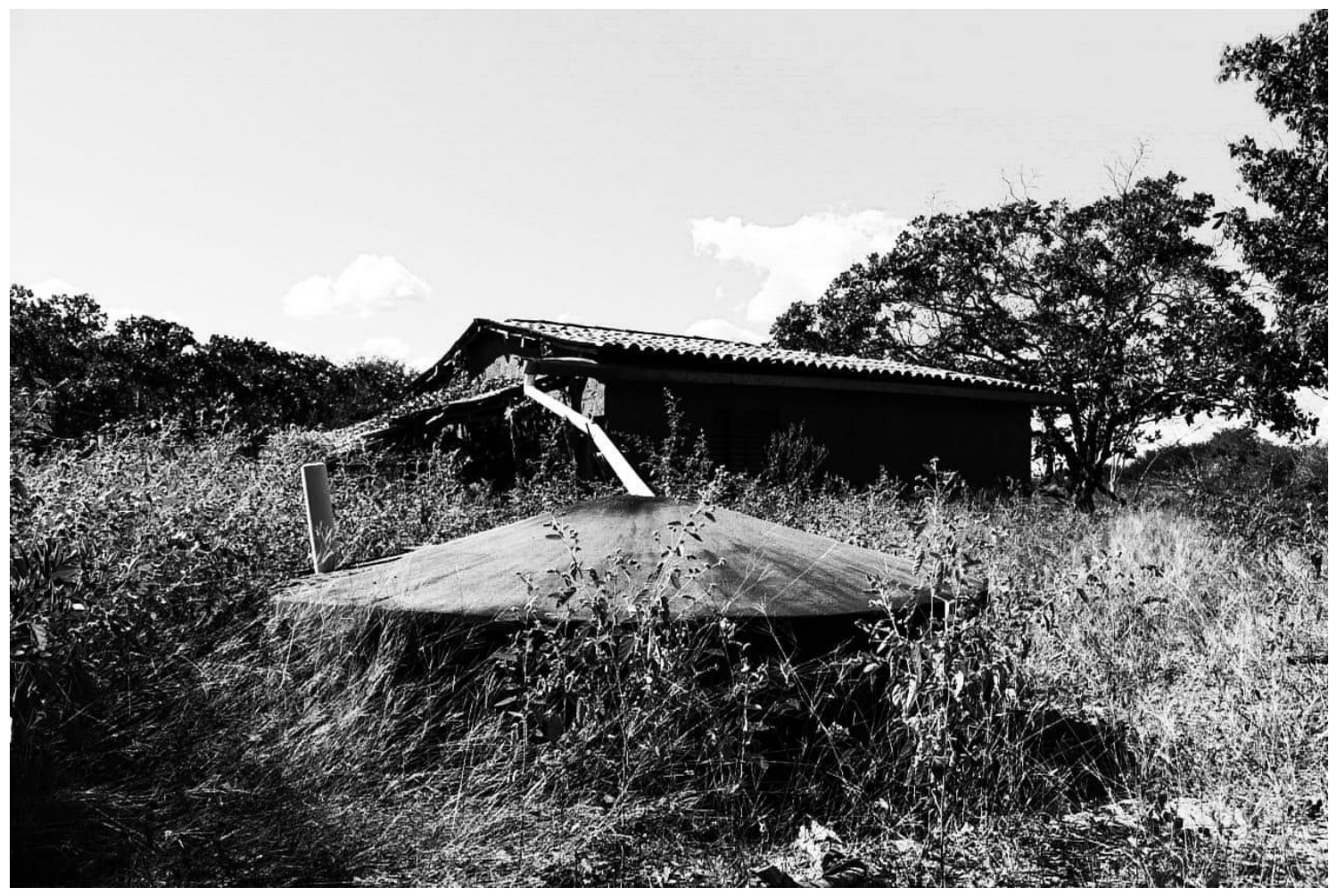




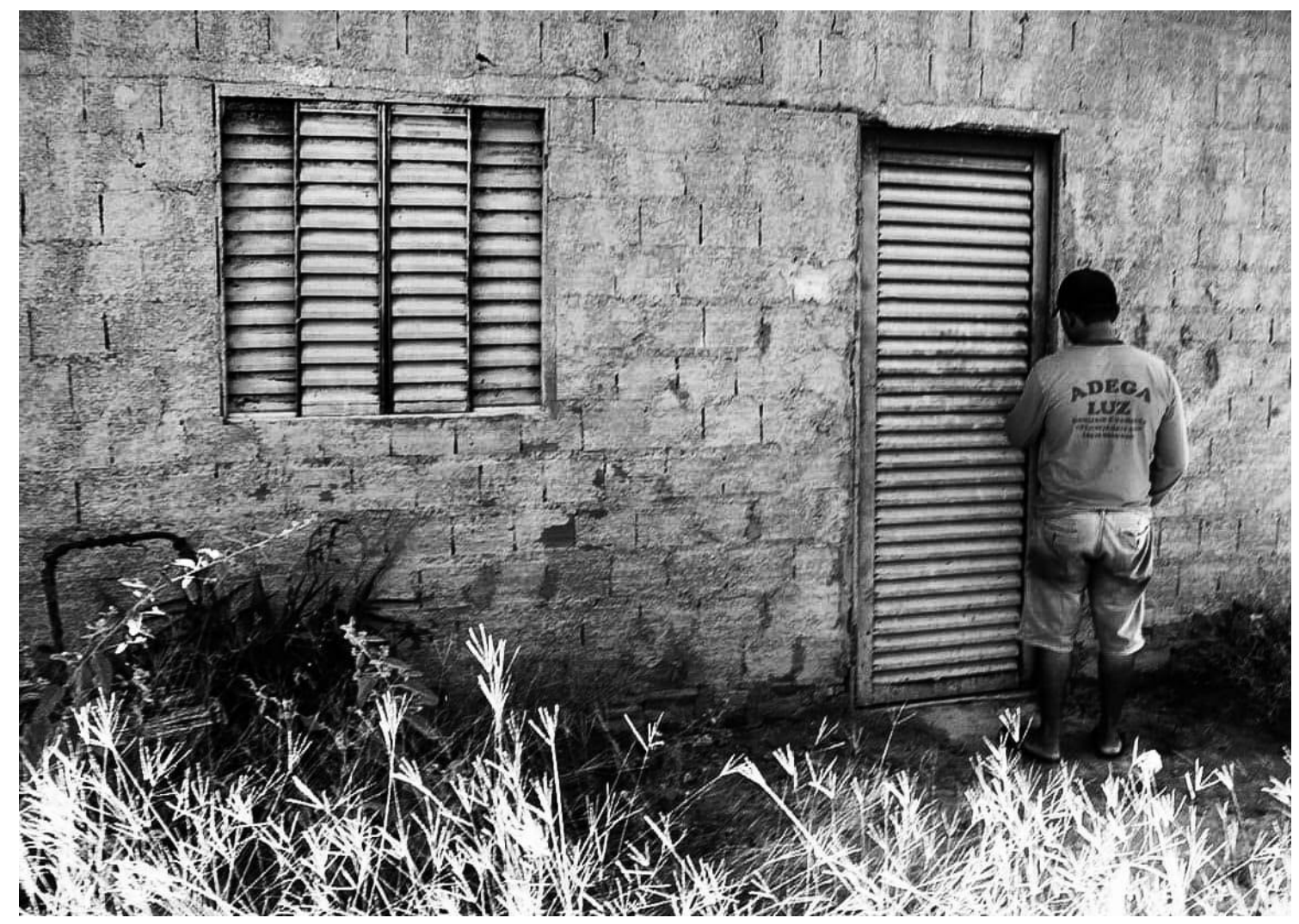

3. As casas vão sentindo o impacto das ausências. Sem manutenção adequada elas passam a abrigar novos moradores como morcegos e insetos.

4. Dentro das casas é possível ver objetos que outrora foram utilizados pela família cotidianamente tanto na roça quanto dentro de casa.

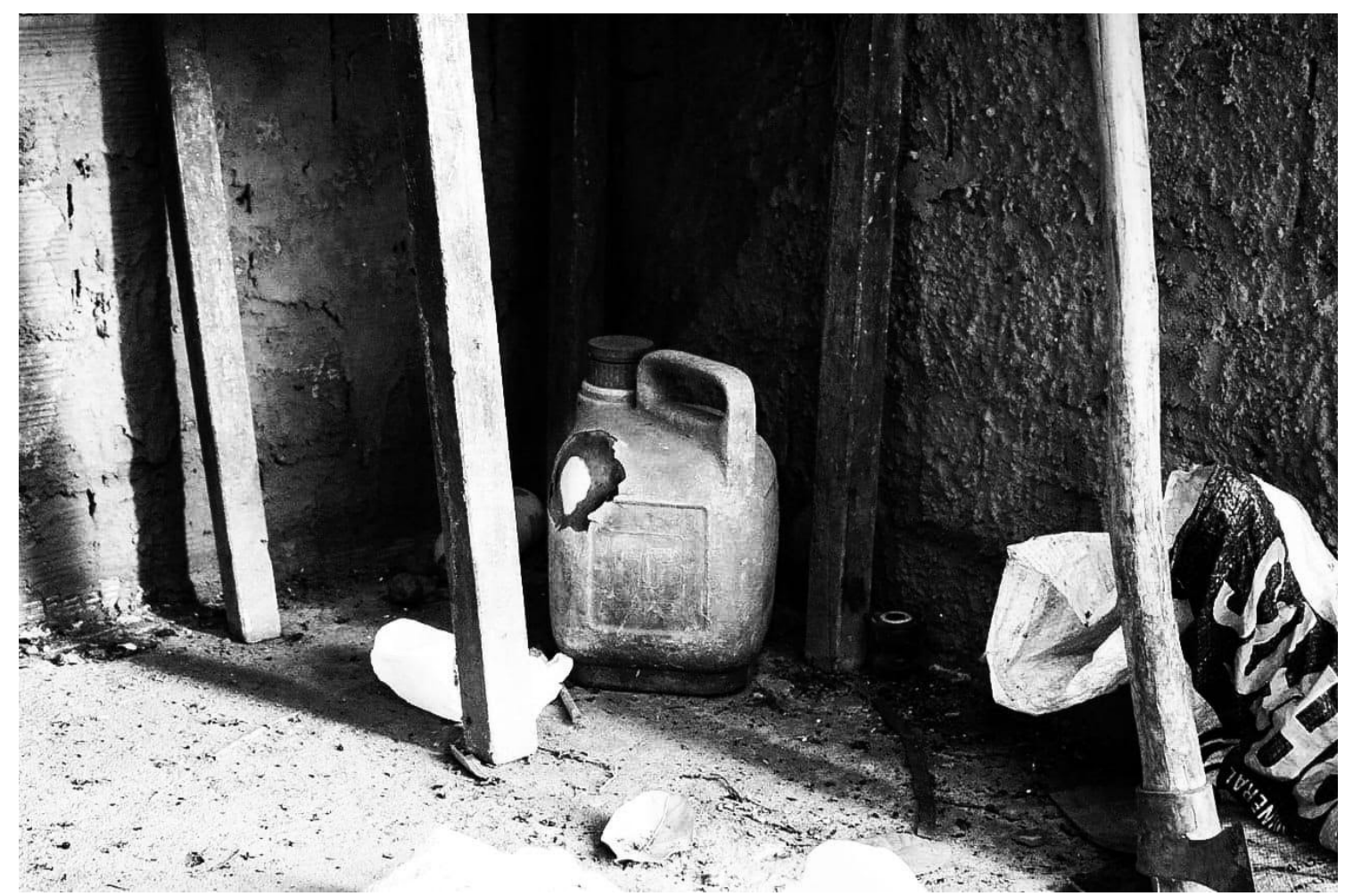




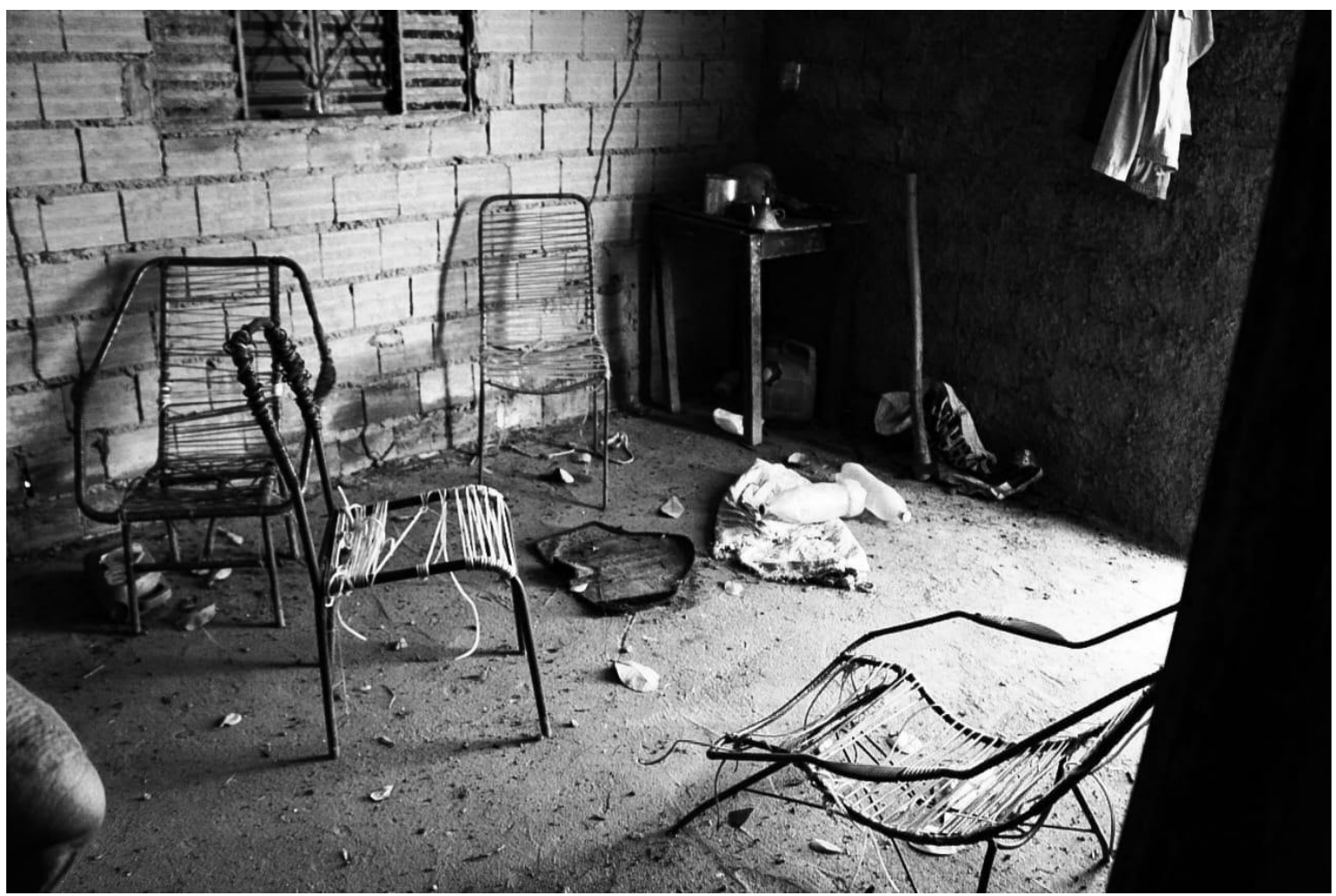

5. Dona Nita se recusava a jogar qualquer objeto fora. Ela afirmava que foram comprados com muita luta e que apesar de não utilizados deveriam ali permanecer.

6. Dona Nita mostrava orgulhosa o instrumento que era utilizado pelo falecido marido para plantar feijão e milho.

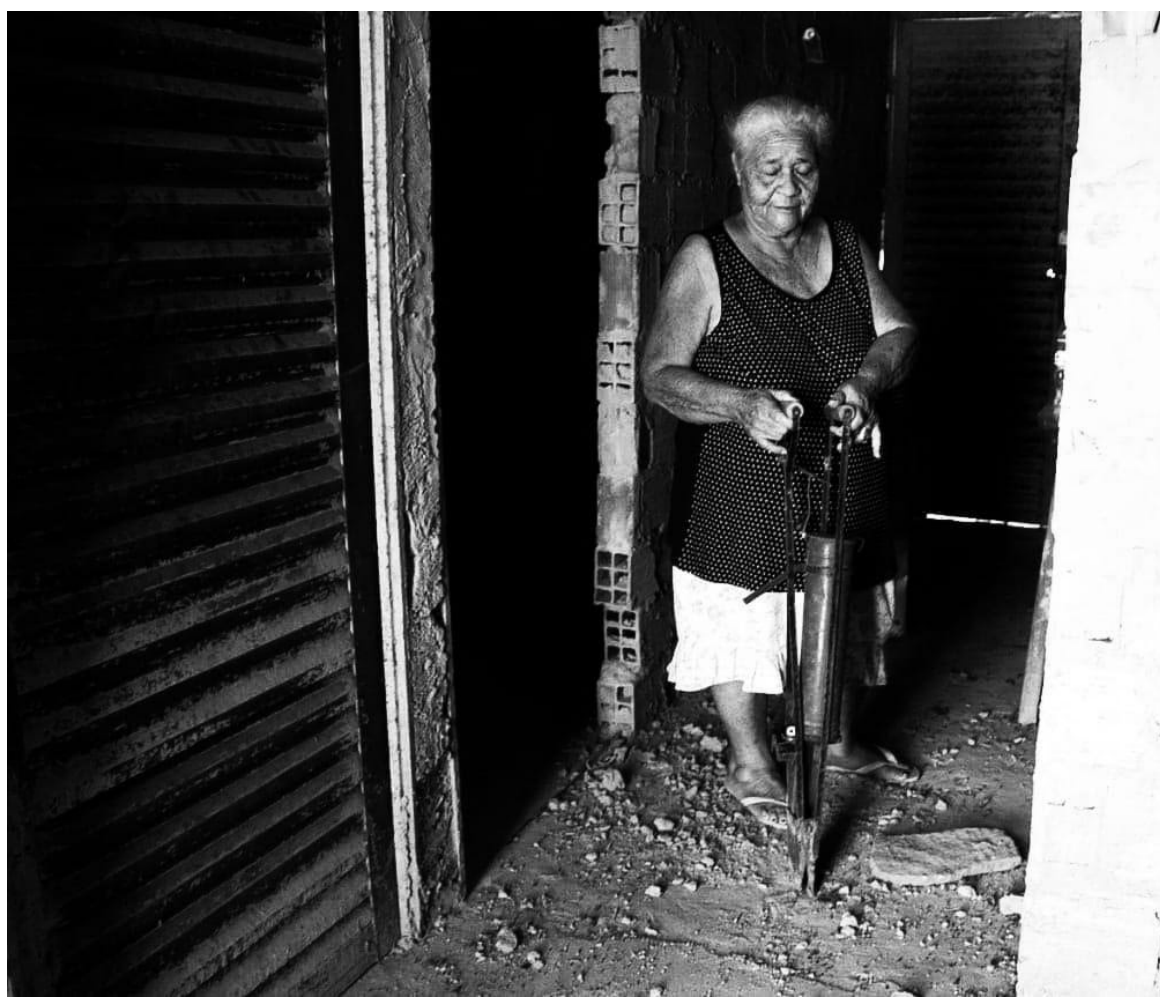




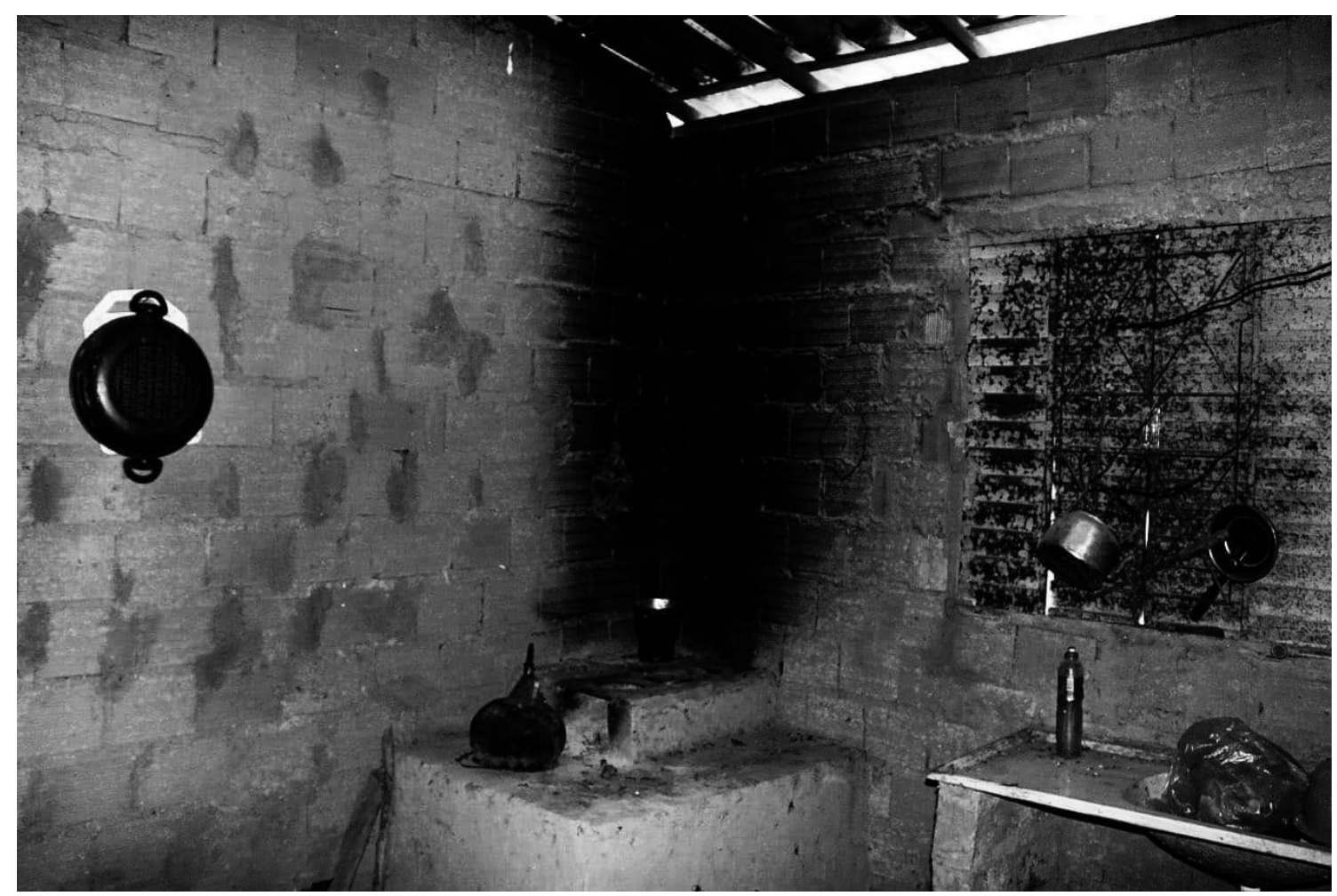

7. $\bigcirc$ fogão de lenha ainda guardava as marcas de quando Dona Nita cozinhava para os filhos e o marido que à época era vivo.

8. As estradas para outras roças começavam a sumir em meio a vegetação (que assumia o protagonismo do espaço lembrando dos filhos que foram para o mundo e não voltavam para a origem).

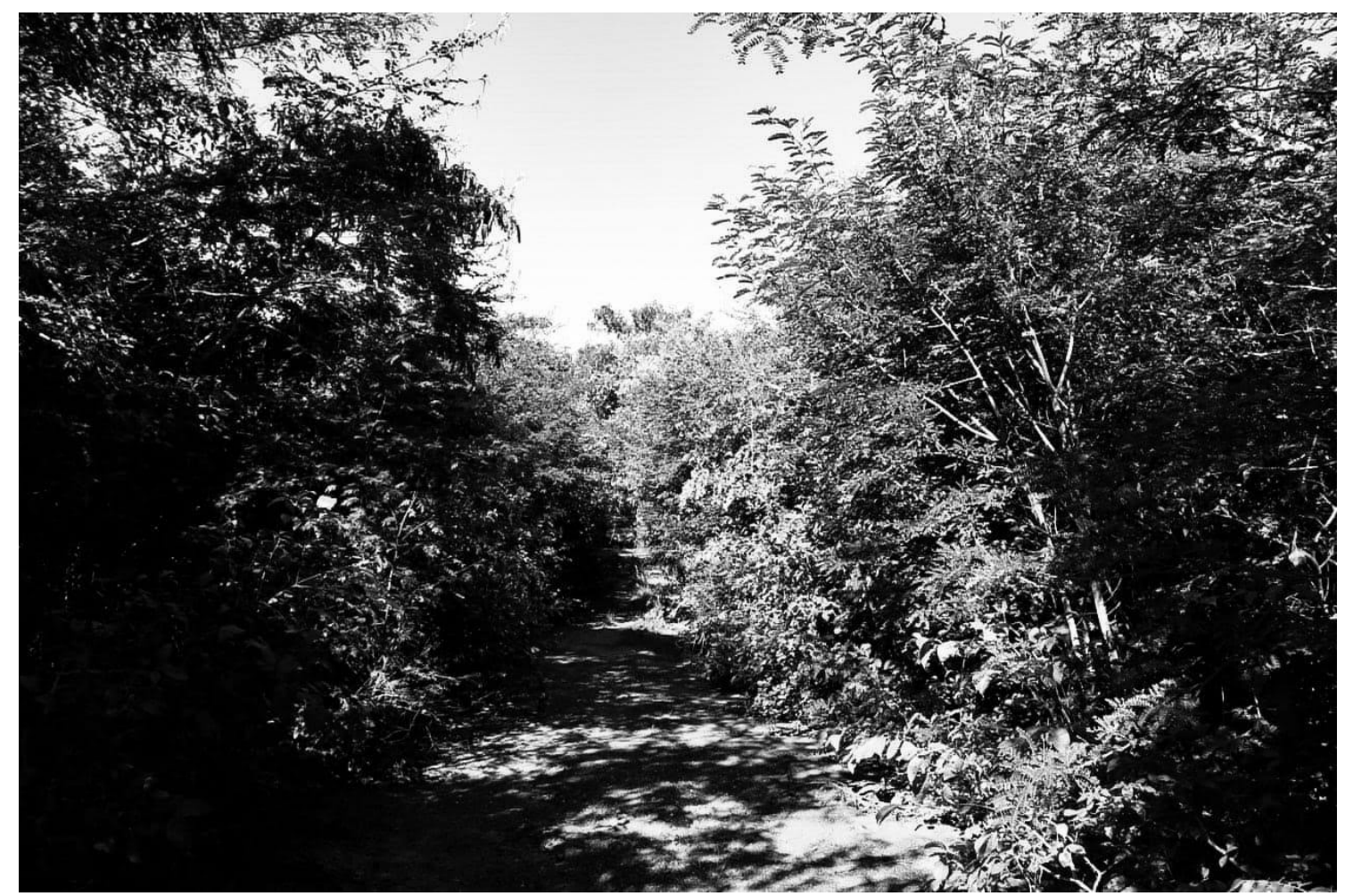




\section{Referências Bibliográficas:}

LOBO. Andréa. 2014. Tão Longe e Tão Perto. Famílias e Movimentos na Ilha de Boa Vista de Cabo Verde. Brasília: ABA Publicações.

SARTI, Cynthia. 1994. A família como espelho: um estudo sobre a moral dos pobres na periferia de São Paulo. Tese de Doutorado. Universidade Federal de São Paulo. Faculdade de Filosofia, Letras e Ciências Humanas. Departamento de Antropologia.

VIRGÍlLIO, Nathan. 2018. Pensa que é só dar o de-comer? Criando e pelejando com parente e bicho bruto na comunidade do Góis-CE. Dissertação de Mestrado, Universidade Federal do Rio de Janeiro, Museu Nacional.

WOORTMANN, Klass. 1990. "Migração, família e campesinato". Revista Brasileira De Estudos De População 7(1):35-53.

Enviado: 25 de junho de 2020 Aceito: 17 de novembro de 2020 